\title{
Mixing process influence on thermal and rheological properties of NBR/SiO2 from rice husk ash
}

\author{
Ana Maria Furtado de Sousa ${ }^{1 *}$, Augusto Cesar de Carvalho Peres ${ }^{2}$, Cristina Russi Guimarães Furtado ${ }^{1}$ and \\ Leila Lea Yuan Visconte ${ }^{3}$
}

\begin{abstract}
'Instituto de Química, Universidade do Estado do Rio de Janeiro - UERJ, Rio de Janeiro, RJ, Brazil
${ }^{2}$ Centro de Pesquisas e Desenvolvimento Leopoldo Américo Miguez de Mello, Petróleo Brasileiro SA, Rio de Janeiro, RJ, Brazil
\end{abstract}

${ }^{3}$ Instituto de Macromoléculas Professora Eloisa Mano, Universidade Federal do Rio de Janeiro - UFRJ, Rio de Janeiro, RJ, Brazil

*ana.furtado.sousa@gmail.com

\begin{abstract}
Silica was extracted from rice husk ash (RHA) by a sequence of reactions to produce nanosilica. Two laboratory routes, co-coagulation and spray drying, were used to incorporate the nanosilica into the rubber matrix. Samples were characterized regarding filler incorporation efficiency, thermal stability, rheological behavior and morphology. Thermogravimetric analysis showed that spray-drying was the most efficient filler incorporation process and also the presence of silica increased the thermal resistance of the rubber compound when compared to the unfilled rubber. The rheological behavior showed that NBR filled with silica presented higher elastic torque (S'), storage modulus (G') and complex viscosity $\left(\eta^{*}\right)$ than unfilled rubber. The Payne effect was also observed for the composites produced by spray-drying. In addition, the thermal behavior and Payne effect results were supported by the comparison of morphology observed by FEG-SEM analysis.
\end{abstract}

Keywords: co-coagulation, latex, silica, spray-drying.

\section{Introduction}

Silica has been used in many applications, including electronics, ceramics and polymer materials. The incorporation of well dispersed silica particles into polymer matrixes is a particularly important way to improve the thermal and mechanical properties of polymers. Furthermore, it is well known that rheological properties can change when fillers are incorporated in a polymer matrix, depending on the kind of filler and the way that it is incorporated. Thus, this knowledge is important to tailor polymer composites with potential applications in numerous technological fields ${ }^{[1-5]}$.

Specifically in the rubber industry, silica is one of the reinforcing fillers widely used in compounds. It is alternative reinforcing filler used to improve some of the properties, such as to impart reduced heat buildup and high tear strength, tensile strength and abrasion resistance. However, a problem with conventional silica-reinforced rubber is that it is normally highly aggregated due to filler-to-filler interactions, resulting in a lower dispersion within the rubbery matrix and poor mechanical properties. The silicas normally used in rubber compounds can be of the precipitated or pyrogenic type, and are normally added to the compounds by open mixers or in internal mixers ${ }^{[6,7]}$.

Recent studies have been devoted to mixtures of silica with rubber via a latex system, as an interesting incorporation option. In these processes, silica suspensions are prepared from commercial precipitated and pyrogenic silicas and then are incorporated in rubber by the co-coagulation method. Examples of recent articles published in this respect are: obtainment of blends of epoxidized natural rubber (ENR),

styrene-butadiene (SBR) copolymer and silica ${ }^{[8]}$; investigation of the effect of $\mathrm{pH}$ and mixing time on the incorporation of silica in SBR rubber ${ }^{[9]}$; and preparation of masterbatches of $\mathrm{NR}$ and silica ${ }^{[10]}$. Besides the co-coagulation method, another technique for blending silica in rubber that also uses latex is the in situ generation of silica through the sol-gel reaction using tetraethoxysilane (TEOS). This method has proved to be highly efficient experimentally for dispersion of silica through reduced formation of aggregates ${ }^{[11,12]}$.

The purpose of this study was to investigate the incorporation of nitrile rubber (NBR) via a latex system with silica sol, employing two mixing methods, co-coagulation and spray drying. In order to verify the process's influence, samples from each process were characterized for filler incorporating efficiency, thermal stability, rheological behavior and morphology. Furthermore, the procedure to prepare silica sol from rice husk ash (RHA) and its characterization is also presented.

\section{Materials and Methods}

\subsection{Materials}

The acrylonitrile butadiene copolymer (NTL615) latex with $33 \%$ acrylonitrile and solid content of $25 \%$ was kindly supplied by Nitriflex SA. Rice husk ash (RHA) was supplied by Empresa Brasileira de Pesquisa Agropecuária (Embrapa). The inorganic content of RHA was $72 \%$ and the chemical composition obtained by X-ray fluorescence 
(XRF, Bruker-AXS, model S4) was 95.30 SiO2; $1.70 \mathrm{~K} 2 \mathrm{O}$; $1.70 \mathrm{Na} 2 \mathrm{O} ; 0.91 \mathrm{P} 2 \mathrm{O} 5 ; 0.74 \mathrm{CaO} ; 0.61 \mathrm{MgO} ; 0.20 \mathrm{MnO}$; $0.12 \mathrm{SO} 3 ; 0.10 \mathrm{Fe} 2 \mathrm{O} 3$ and $0.01 \mathrm{Rb} 2 \mathrm{O}$ (\% by weight). This RHA has a high amount of silica $(95.33 \%$ ) and a few impurities, which were predominantly $\mathrm{K} 2 \mathrm{O}$ and $\mathrm{Na} 2 \mathrm{O}$. Cation exchange resin Amberlite-120 was supplied by Vetec Quimica Fina. Analytical grade sodium and potassium hydroxide, sulfuric acid and aluminum sulfate were used as received. Sulfuric acid and aluminum sulfate were used to prepare the coagulant bath solution.

\subsection{Silica sol production}

The silica sol used in this work was synthesized in our laboratory using rice husk ash (RHA) as raw material. The procedure used can be divided into three parts. First, RHA $(150 \mathrm{~g})$ was reacted with sodium hydroxide $\left(0.8 \mathrm{~mol} \mathrm{~L}^{-1}\right)$ at $100{ }^{\circ} \mathrm{C}$ to produce a sodium silicate solution with $\mathrm{SiO}_{2} / \mathrm{Na}_{2} \mathrm{O}$ mole ratio of $\sim 3$. Five laboratory-sized batches were prepared and at the end, all reaction products were mixed to give just one water glass solution, which was characterized for $\mathrm{SiO}_{2} / \mathrm{Na}_{2} \mathrm{O}$ mole ratio, silica content, $\mathrm{pH}$ and density. Second, the water glass solution was passed through an ion exchange column filled with Ambertile-120 to allow the sodium ions to be replaced by hydrogen ions at the exchange sites of the cation resin, thus giving rise to an aqueous solution of active silicic acid with $\mathrm{pH}$ between 2 and 3. Finally, the active silicic acid was added (flow rate of $10 \mathrm{~mL} \cdot \mathrm{min}^{-1}$ ) to a $10 \mathrm{~mL}$ of $\mathrm{KOH}$ solution $(10 \% \mathrm{wt})$ previously heated to $60{ }^{\circ} \mathrm{C}$, in order to perform the nucleation, polymerization and particle growth of silica sol. In this part of the procedure, eight laboratory-sized batches of $100 \mathrm{~mL}$ were produced and all products were characterized for silica sol particle size distribution, silica content and $\mathrm{pH}$.

\subsection{Nitrile rubber (NBR) filled silica production}

To obtain the nitrile rubber filled with silica, $500 \mathrm{~mL}$ of NBR latex were mixed with the necessary amount of silica sol so as to have $2.5 \mathrm{phr}$ and $5.0 \mathrm{phr}$ of silica in the composition. First, the previously calculated latex and silica sol amounts were mixed and stirred for 2 hours. Next, the colloidal suspensions were kept for maturation at $23{ }^{\circ} \mathrm{C}$ for 24 hours, a process which could be performed without disturbing the colloidal stability since the $\mathrm{pH}$ values of NBR latex and silica sol were in the range of 10-11. The maturation step was necessary to give some time for the different particles present in these colloidal systems to adjust and co-exist in the new environment. Additionally, it allows air to escape and some particles to migrate into the micelle. As an example, in dipping and foam process, the maturation period is usually $10-20$ hours and 2-3 days, respectively ${ }^{[13]}$.

After that, two different processes, co-coagulation (CC) and spray drying (SD) were used as to occlude the silica particles inside the rubber during the destabilization of the system. In order to analyze the effects of silica content on the rheological and thermal properties of the rubber-silica blends, both procedures were also carried out with the NBR latex without any silica.

\subsubsection{Co-coagulation (CC)}

The co-coagulation experiments were carried out by adding the mixed colloidal silica/latex, at constant flow rate $\left(50 \mathrm{~mL} \cdot \mathrm{min}^{-1}\right)$ under stirring (2400 RPM), to a coagulant bath solution. At the end of the coagulation process, the powdered NBR-silica was vigorously washed with distillated water until all residual acid was completely removed. Finally, the particles were separated by filtration and dried in an air-circulating oven at $100{ }^{\circ} \mathrm{C}$ for 1 hour.

\subsubsection{Spray-drying (SD)}

Volumes of the prepared colloidal silica/latex were atomized and dried in a Büchi B290 Mini Spray Dryer. The parameters for the spray drying process were as follows: air inlet temperature of $200{ }^{\circ} \mathrm{C}$; air outlet temperature of $110{ }^{\circ} \mathrm{C}$; aspirator set at $80 \%$; pumper at $25 \%$ and nozzle cleaner 6 .

\subsection{Characterization}

Dynamic light scattering (DLS) studies were conducted using a Malvern Zetasizer Nano ZS instrument.

Thermogravimetric analyses (TGA) were recorded with a TA Instruments analyzer at a heating rate of $20^{\circ} \mathrm{C} / \mathrm{min}$, under air atmosphere.

Fourier-transform infrared (FTIR) spectra were record with a Perkin-Elmer Spectrum One spectrometer with ATR Spectrum software V5.3.1.

The rheology of the silica-rubber particles was investigated using rubber process analyzer (RPA 2000, Alpha Technologies, USA). For each test, two samples from each experiment were tested with two consecutive sweeps, one immediately following the other. Part of this test protocol was based on ASTM D6204. The procedure was as follows: (i) The sample was placed on the lower die and the cavity was closed; (ii) a pre-conditioned step was performed at $5 \mathrm{~Hz}, 2.8^{\circ}, 100{ }^{\circ} \mathrm{C}$ during 4 minutes; (iii) the first strain sweep was carried out at $5 \mathrm{~Hz}$ and $100{ }^{\circ} \mathrm{C}$, by applying a sequence of strain steps from 1 to $1259 \%$ (i.e., strains from $0.07^{\circ}$ to $89.9^{\circ}$ ); (iv) the second strain sweep was carried out using the same parameters as the first strain sweep.

The morphology of the silica particles in the NBR matrix was investigated by field emission gun-scanning electron microscopy (FEG-SEM) performed with a FEI QUANTA 450 microscope. Samples were coated with platinum.

\subsection{Data analysis}

Data analysis was performed using the software Statistica 8 (StatSoft).

\section{Results and Discussions}

\subsection{Silica sol preparation from $R H A$}

The sodium silicate (water glass) produced from RHA had silica content of $6.9 \pm 0.2 \mathrm{~g} / 100 \mathrm{~mL}$; density of $1.072 \pm 0.001 \mathrm{~g} / \mathrm{cm}^{3} ; \mathrm{pH}$ of 11.8 and $\mathrm{SiO}_{2} / \mathrm{Na}_{2} \mathrm{O}$ mole ratio of $2.8 \pm 0.2$. These data indicated that $\mathrm{SiO}_{2} / \mathrm{Na}_{2} \mathrm{O}$ mole ratio and silica content were close to the recommended values for the water glass properties to be used for silica sol 
production, which are: silica content of $2-6 \%$ and $\mathrm{SiO}_{2}: \mathrm{Na}_{2} \mathrm{O}$ mole ratio close to $3.1^{[3]}$.

Table 1 shows the individual results of the each batch run of silica sol produced. According to DLS measurements, all experimental runs showed monodisperse particles of silica sol, whose mean diameters ranged, respectively, from 3.3 to $7.6 \mathrm{~nm}$ and from 2.6 to $7.1 \mathrm{~nm}$ for volume and number distributions.

\subsection{Nitrile rubber (NBR) filled silica production}

The actual silica content of each experiment was determined by TGA analysis (three replicated runs for each experiment) as the percent residue at $950{ }^{\circ} \mathrm{C}$. Additionally, TGA was also used to determine the initial degradation temperature by using the extrapolated onset temperature method.

The actual silica amount present in the rubber matrix and the initial degradation temperature (the confidence interval for the mean) for each experiment are shown in Table 2.

Regarding silica content, the co-coagulation process was less efficient in the filler incorporation than the spray drying, since the amount of silica incorporated in the first process was lower than the theoretical predefined values. We also observed that the amounts of silica incorporated by the co-coagulation process were exactly the same, regardless the initial amount used. This outcome suggests that only particles which have been adsorbed during the maturation step remained in the rubber composition, and probably the particles that were dragged and trapped during the latex coagulation did not have enough adhesion with the rubber and they were probably removed during the washing step. Concerning the high efficiency of the spray-drying process, the results were as expected since it is a closed process, thus no material loss usually happens. Furthermore, there is no washing step in this process. An important comment that should be highlighted is the fact that $\mathrm{CC}$ process showed a maximum limit of silica incorporation considering the experimental parameters used in the present research. Because of that, it is not possible to discuss the effect of silica content increase in the products of CC process. Additionally, it is not also possible to perform comparisons between CD and SD processes regarding specifically the effect of silica content. However, each process can be analyzed individually and the SD and $\mathrm{CC}$ process can be compared regarding the unfilled rubber characteristics.

As for initial degradation temperatures, presented in Table 2, two comments can be made: (a) the unfilled NBR samples started to undergo thermal degradation at the same temperature intervals; regardless the process used, and (b) for each process the presence of silica in the rubber matrix increased the initial degradation temperature of the samples. The improvement of the thermal resistance of the CC and SD filled compounds compared to their respective unfilled ones can be explained by the fact that filler absorbed heat energy and, consequently, a retard of the heat transfer from the filler to the rubber chains occurs. It is also important to highlight this phenomena depends on the filler dimension and on the degree of the filler dispersion in the rubber matrix ${ }^{[14-17]}$.

Changes in rubber behavior caused by the processability history can be evaluated by elastic torque response (S') at high strains in the nonlinear viscoelastic region ${ }^{[18]}$. The elastic torque response ( $\left.\mathrm{S}^{\prime}\right)$ of the first (1a Sw) and the second (2a Sw) strain sweeps of the all experiments produced by co-coagulation (CC) and spray-drying $(\mathrm{SD})$ routes are shown in Figure 1.

Regarding the CC process, it can be seen from Figure 1a that co-coagulation produced unfilled and filled rubber compounds with the same rheological curve pattern. Here, the S' torque rises with increasing strain, reaches a maximum

Table 1. Properties of silica sol obtained from RHA.

\begin{tabular}{ccccc}
\hline \multirow{2}{*}{ Batch number } & pH & Silica g.mL $\mathbf{~}^{-1}$ & \multicolumn{2}{c}{ Distribution of Particle Diameter, $\mathbf{n m}$} \\
\cline { 4 - 5 } & 11.0 & 0.055 & Volume & Number \\
\hline 1 & 10.5 & 0.050 & 5.7 & 5.4 \\
3 & 10.1 & 0.052 & 7.6 & 7.1 \\
4 & 10.4 & 0.062 & 3.3 & 2.6 \\
5 & 10.1 & 0.071 & 4.4 & 4.0 \\
6 & 10.0 & 0.073 & 4.0 & 3.6 \\
7 & 10.3 & 0.072 & 4.3 & 3.6 \\
8 & 10.3 & 0.054 & 3.8 & 3.1 \\
Mean & $\mathbf{1 0 . 0} \pm \mathbf{0 . 3}$ & $\mathbf{0 . 0 6 1} \pm \mathbf{0 . 0 0 8}$ & $\mathbf{4 . 7} \pm \mathbf{1 . 1}$ & $\mathbf{4 . 1} \pm \mathbf{1 . 4}$ \\
\hline
\end{tabular}

Table 2. Silica content and initial degradation temperature for the products of CC and SD processes.

\begin{tabular}{cccc}
\hline \multirow{2}{*}{$\begin{array}{c}\text { Experiment } \\
\text { Code }\end{array}$} & \multicolumn{2}{c}{ Silica content, phr } & $\begin{array}{c}\text { Initial degradation } \\
\text { temperature, }{ }^{\circ} \mathbf{C}\end{array}$ \\
\cline { 2 - 3 } CC-NBR & Theoretical values & Experimental values & $369-378$ \\
CC-1 & 0.0 & - & $385-394$ \\
CC-2 & 2.5 & $1.2 \pm 0.3$ & $384-394$ \\
SD-NBR & 5.0 & $1.2 \pm 0.1$ & $369-377$ \\
SD-1 & 0.0 & - & $378-387$ \\
SD-2 & 2.5 & $2.3 \pm 0.2$ & $377-386$ \\
\hline
\end{tabular}


torque in both first and second sweeps at high strains, with overlap of the curves. These results indicate that the high deformations and amount of work applied to the samples during the first strain sweep did not modify their rheological properties. Moreover, the presence of silica in the rubber increased the $S$ ' torque, reaching higher values than those observed for the unfilled rubber. Since all rubber samples were uncured, those higher values of S' torque observed show that the presence of silica is responsible for making the rubber compound samples more elastic when they are submitted to high strains. Moreover, as expected, there is no difference on the $\mathrm{S}$ ' torque the curves of CC-1 and CC-2 since the amount of silica presented in both compositions are practically the same, as previously reported in Table 1 .

According to the rheological behavior of the materials produced by spray drying, as shown in Figure 1b, two different curve patterns were found. For the unfilled NBR sample, in the first strain sweep, the S' torque increased, reached a maximum near $300 \%$ strain and after that point it started to decrease. In addition, for this sample, the first and second strain sweep curves are not superimposed, indicating that the first high strain sweep altered the rheological property of unfilled NBR. This can be attributed to a reduction of the chain entanglement during the test. On the other hand, for the silica-rubber samples (SD-1 and SD-2), the S' torque continually rises with increasing strain, reaches a maximum torque in both first and second high strain sweeps, with overlapping curves. The change of the curve pattern as well as the higher values of S' torque of silica-rubber samples when compared to the unfilled NBR obtained from SD process show a reinforcing behavior and indicate an interaction between rubber and silica.

By comparing the unfilled compounds, Figure 1a (CC-NBR) and $1 \mathrm{~b}$ (SD-NBR), it can be verified that the process affected the rheological properties of unfilled NBR. That result can be attributed to the fact that spray drying is a closed process, so additives used in the polymerization tend to remain in the rubber, contributing to the $S$ ' torque reduction at high deformations. In order to investigate the above supposition, FTIR was performed for unfilled NBR from the co-coagulation and spray-drying processes, as shown in Figure 2. Looking at the two spectra, a new band at $1685 \mathrm{~cm}^{-1}$, corresponding to the carbonyl stretching vibration band of $\mathrm{C}=\mathrm{O}$, appears in the spray-drying spectrum, which can indicate the presence of the polymerization additives. Another possible reason, which could explain the appearance of presence of the band at $1685 \mathrm{~cm}^{-1}$ in FTIR is the occurrence of the NBR thermal degradation during the spraying-dryer process. However, this hypothesis was refuted because the initial degradation temperatures of unfilled NBR produced by $\mathrm{CC}\left(369-378^{\circ} \mathrm{C}\right)$ and $\mathrm{SD}\left(369-377^{\circ} \mathrm{C}\right)$ are practically the same, independently of the process used.

Measurement of the modulus decrease with increasing strain amplitude by dynamic mechanical testing is commonly used to investigate the reinforcing mechanism occurring in filled rubber compounds ${ }^{[19-21]}$. Figure 3 shows the storage shear modulus $\left(G^{\prime}\right)$ versus the strain amplitude for the co-coagulation and spray-drying experiments. Regarding the influence of the silica presence on the $\mathrm{G}$ ', as expected for co-coagulation process, the CC-1 and CC-2 showed similar values of G' since they have the same amount of silica. For spray-drying process, the curves showed a relationship with the silica amount, which means that, the higher the silica content is, the higher the $\mathrm{G}^{\prime}$ is.

For all unfilled and filled compounds studied in this work, two notable results were found: (a) unfilled NBR samples showed lower modulus values than silica/NBR, regardless of the process used; and (b) CC-NBR showed lower modulus values than SD-NBR.

In general, the increase in storage shear modulus due to the presence of silica in a rubbery matrix can be explained by

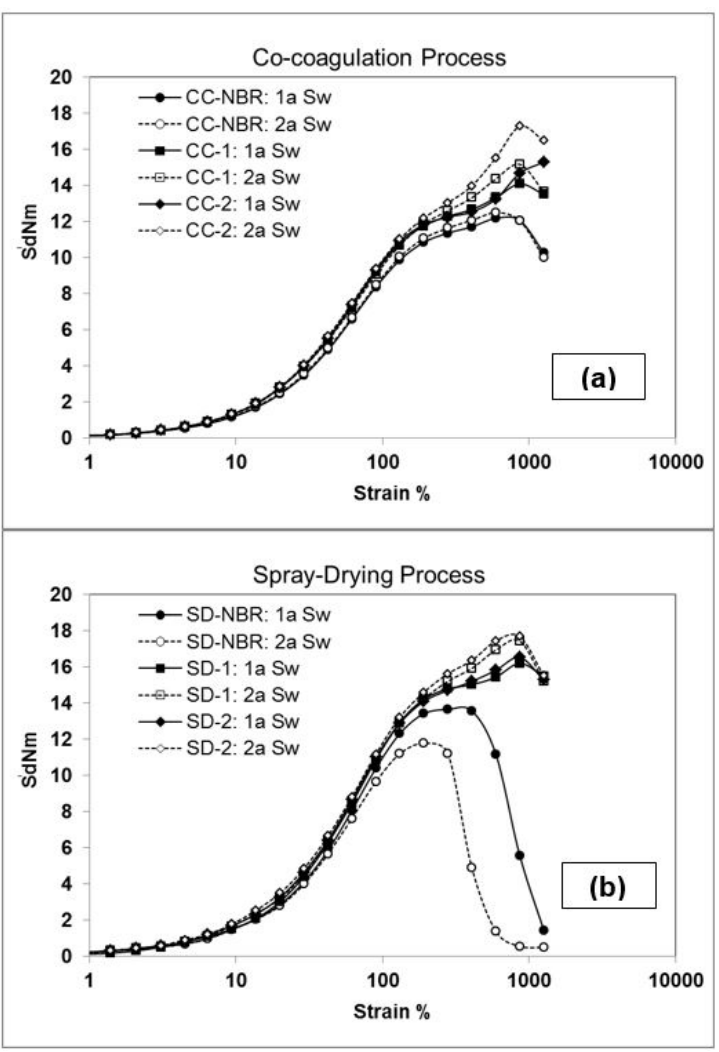

Figure 1. Elastic torque response (S') versus shear strain amplitude of the first (1a Sw) and the second (2a Sw) strain sweep for all samples prepared by (a) co-coagulation (CC) and (b) spray-drying (SD).

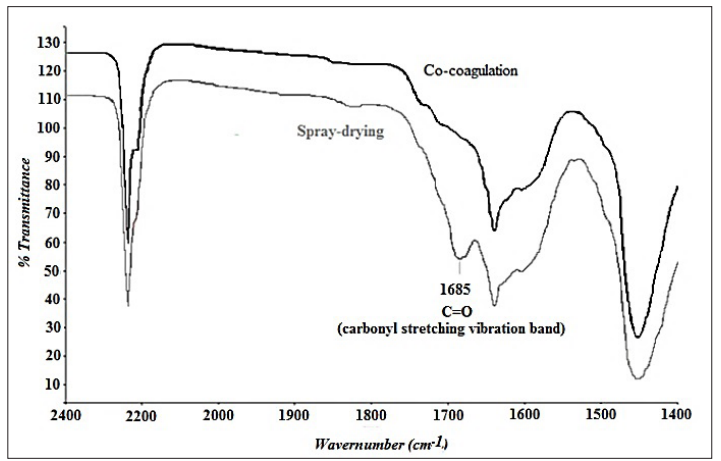

Figure 2. FT-IR spectra of unfilled NBR produced by co-coagulation and spray-drying. 
the contribution of the hydrodynamic effect and filler-filler interactions. The influences of polymer network generated by vulcanization and filler-polymer interaction were not considered in this case, since all samples tested were uncured and no coupling agent was used. About hydrodynamic effect, the increase in modulus results from the fact that fillers form a rigid phase that cannot be deformed. As for the filler-filler interaction, known as the Payne effect, it is characterized by a modulus decrease at low strain caused by the breakdown of filler inter-aggregates ${ }^{[18-20]}$. For silica filled NBR compounds, it is commonly understood that filler-filler networking takes place easily due to the polarity differences between polymer and silica.

From Figure 3, it can be seen that the Payne effect was not as pronounced for the silica/NBR samples produced by co-coagulation, since no decay of G' modulus was observed until near $40 \%$ of strain. That result may indicate that the silica particles did not form aggregates with sufficient size to be detected.

As for the spray-drying process, the non-linearity of G' modulus was clearly verified, principally for uncured NBR with 5.0 phr of silica, indicating that by using the spray-drying process, the filler-filler interaction increased as silica content rose.

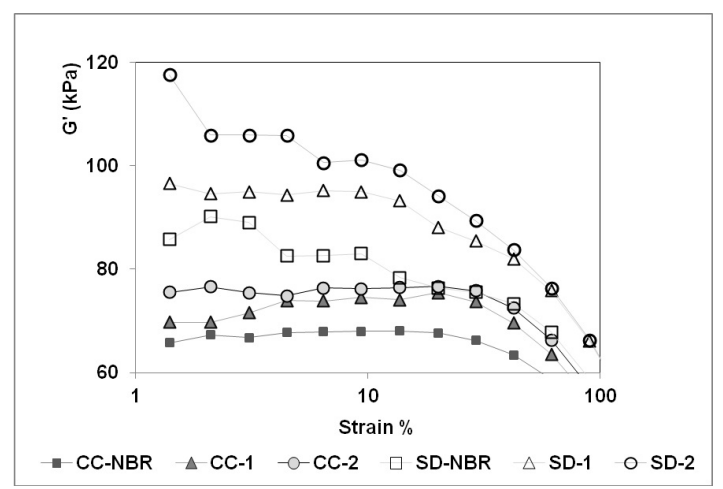

Figure 3. Storage shear modulus versus shear strain amplitude of samples prepared by co-coagulation and spray-drying processes.
Regarding the process influence on the unfilled rubber storage modulus ( $\left.G^{\prime}\right)$, it can be attributed to the fact that during spray drying the elastomer chains had a higher tendency to undergo physical entanglements than occurred in the co-coagulation process.

Figure 4 shows the complex viscosity $\left(\eta^{*}\right)$ as a function of strain amplitude at $100{ }^{\circ} \mathrm{C}$ for all co-coagulation and spray-drying experiments. Regarding the influence of the silica presence on the $\eta^{*}$, similar outcomes of the storage shear modulus were observed.

Concerning the SD process, it is verified that SD-NBR sample was more sensitive to the strain amplitude deformation. The reduction of the viscosity of the compounds in function of deformation applied can be explained by the reduced chain entanglements, reduced filler-rubber interaction and also the destruction of agglomerates, which facilitated the movement of the chains. In the specific case of the SD-NBR sample, as previously explained, the lower value of the viscosity at higher strains, when compared to the respective filled compounds, can be caused by the presence of additives from the emulsion polymerization (emulsifier/soap and other ingredients usually introduced into the polymerization vessels) that act as plasticizers.

The silica morphology and its dispersion in the rubber matrix were verified by FEG-SEM. Figure 5 (scale bar of $400 \mu \mathrm{m}$ ) shows the photomicrographs of the CC-1 (Figure 5a) and SD-1 (Figure 5b). Regarding CC-process, it can be noted that few silica particles are visible for CC-1. About the SD process, it is possible to see the presence of many large silica particles. Both morphologies support the results of thermal behavior and Payne effect presented.

The evaluation of silica size in sample CC-1 is shown in Figure 6, which presents two photomicrographs with scale bar of $3 \mu \mathrm{m}$ (magnification of 25,000x) and $500 \mathrm{~nm}$ (magnification of 100,000x). According to these images, a broad range of silica particle sizes occurred, from the macro to the nano dimensions.

The silica incorporation in the rubber was confirmed by the presence of a band corresponding to the siliceous material in the FEG-SEM/EDX spectrum of SD-1, as shown

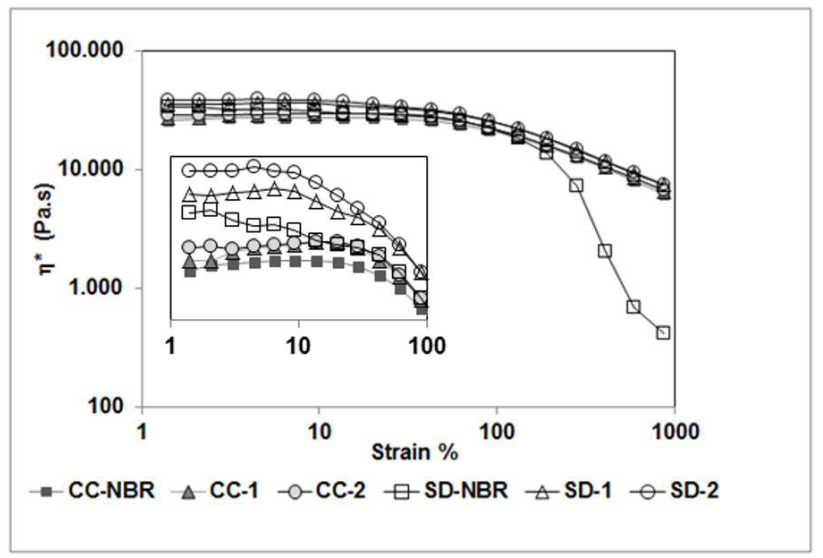

Figure 4. Complex viscosity $\left(\eta^{*}\right)$ versus shear strain amplitude of samples prepared by co-coagulation and spray-drying processes. 


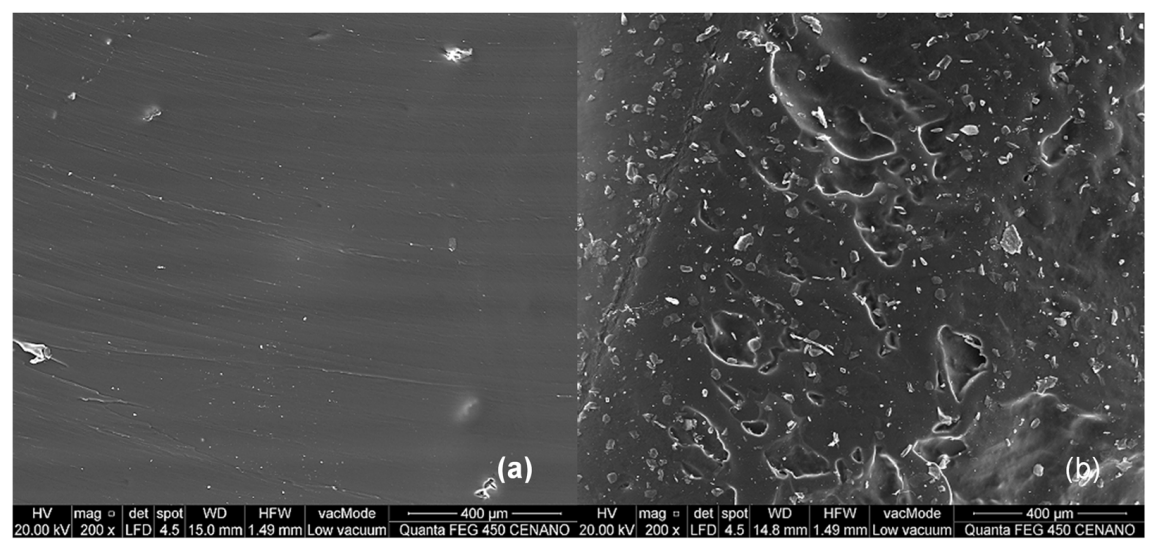

Figure 5. FEG-SEM photomicrograph with scale bar of $400 \mu \mathrm{m}$ (magnification of 200x) of (a) CC-1 and (b) SD-1.

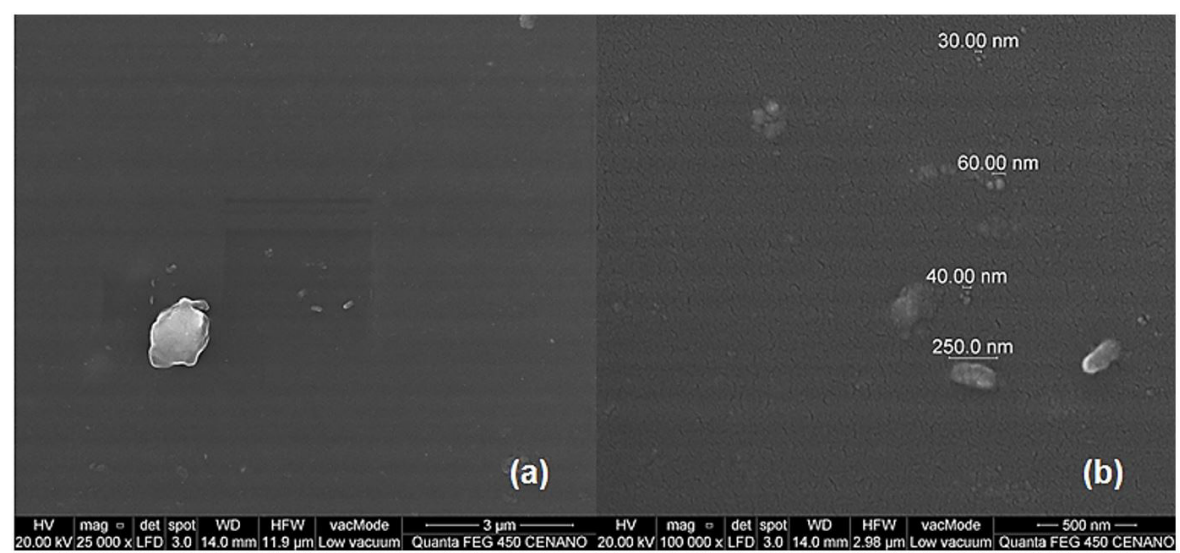

Figure 6. FEG-SEM photomicrograph of CC-1 with scale bar of (a) $3 \mu \mathrm{m}$ and and (b) $500 \mathrm{~nm}$.

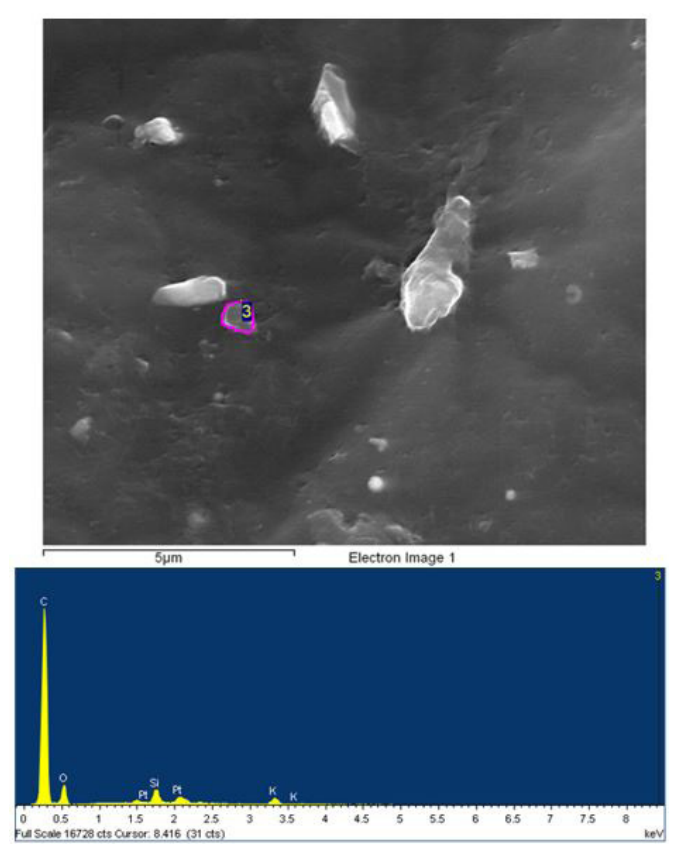

Figure 7. FEG-SEM photomicrograph of SD-1 and the EDX spectrum of particle \#3. in Figure 7. The presence of potassium is explained by the fact that it is a counter-ion of the colloidal silica particle.

\section{Conclusions}

Nitrile rubber filled silica from rice husk ash (RHA) was prepared by using co-coagulation and spray-drying processes. Regarding the actual silica content of the compounds, under the experimental conditions used, only the spray drying was efficient concerning the silica content incorporation.

According to the thermal degradation temperatures, an improvement in thermal behavior of nitrile rubber occurred due to the presence of silica in rubber matrices.

About rheological behavior, all filled and unfilled rubber particles in the samples produced by co-coagulation exhibited the same rheological curve pattern and the presence of silica in the rubber matrix increased the $S$ ' torque.

For the spray-drying process, two different S' torque curve patterns were observed, being that difference ascribed to the by the presence of additives used in the polymerization and silica-rubber interaction. Also, the higher values of the storage modulus (G') and Complex viscosity $\left(\eta^{*}\right)$ observed for unfilled spray-dried product was attributed to the physical entanglements produced during the process. In addition, 
the Payne effect increased as the silica content rose in the samples produced by spray drying.

FEG-SEM analysis showed that co-coagulation produces well silica dispersed compound with lower silica aggregate formation.

This study also demonstrated that RHA waste has potential as raw material to prepare silica sol, which is a nanomaterial with potential use in many applications.

\section{Acknowledgements}

We thank the Instituto Nacional de Tecnologia (INT) for performing the FEG-SEM and Fundação de Amparo à Pesquisa do Estado do Rio de Janeiro (FAPERJ) for financial support.

\section{References}

1. Rocha, T. L. A., Jacobi, M. M., Samios, D., \& Schuster, R. H. (2006). Evaluation of the influence of the polymer-filler interaction on compounds based on epoxidized elastomeric matrix and precipitated silica. Polimeros: Ciência e Tecnologia, 16(2), 111-115. http://dx.doi.org/10.1590/S0104-14282006000200010.

2. Pal, K., Rajasekar, R., Kang, D. J., Zhang, Z. X., Pal, S. K., Kim, J. K., \& Das, C. K. (2010). Effect of fillers and nitrile blended PVC on natural rubber/high styrene rubber with nanosilica blends: Morphology and wear. Materials \& Design, 31(1), 25-34. http://dx.doi.org/10.1016/j.matdes.2009.07.023.

3. Hassan, H. H., Ateia, E., Darwish, N. A., Halim, S. F., \& Abd El-Aziz, A. K. (2012). Effect of filler concentration on the physico-mechanical properties of super abrasion furnace black and silica loaded styrene butadiene rubber. Materials \& Design, 34, 533-540. http://dx.doi.org/10.1016/j.matdes.2011.05.005.

4. Taguet, A., Cassagnau, P., \& Lopez-Cuesta, J. M. (2014). Structuration, selective dispersion and compatibilizing effect of (nano)fillers in polymer blends. Progress in Polymer Science, 39(8), 1526-1563. http://dx.doi.org/10.1016/j. progpolymsci.2014.04.002.

5. Pourhossaini, M. R., \& Razzaghi-Kashani, M. (2014). Effect of silica particle size on chain dynamics and frictional properties of styrene butadiene rubber nano and micro composites. Polymer, 55(9), 2279-2284. http://dx.doi.org/10.1016/j. polymer.2014.03.026.

6. Leblanc, J. L. (2002). Rubber-filler interactions and rheological properties in filled compounds. Progress in Polymer Science, 27(4), 627-687. http://dx.doi.org/10.1016/S0079-6700(01)000405.

7. Zhang, C., Liu, L., Zhang, Z. X., Pal, K., \& Kim, J. K. (2011). Effect of silica and silicone oil on the mechanical and thermal properties of silicone rubber. Journal of Macromolecular Science, Part B: Physics, 50(6), 1144-1153. http://dx.doi.org /10.1080/08941920.2010.518533.

8. Pongdong, W., Nakason, C., Kummerlöwe, C., \& Vennemann, N. (2015). Influence of filler from a renewable resource and silane coupling agent on the properties of epoxidized natural rubber vulcanizates. Journal of Chemistry, 2015, 1-15. http:// dx.doi.org/10.1155/2015/796459.

9. Wang, J., \& Wu, Y. (2014). Preparation of silica-reinforced styrene-butadiene rubber via co-coagulation process. Journal of Elastomers and Plastics, 46(2), 144-155. http://dx.doi. org/10.1177/0095244312465277.

10. Prasertsri, S., \& Rattanasom, N. (2012). Fumed and precipitated silica reinforced natural rubber composites prepared from latex system: mechanical and dynamic properties. Polymer Testing, 31(5), 593-605. http://dx.doi.org/10.1016/j. polymertesting.2012.03.003.

11. Sittiphan, T., Prasassarakich, P., \& Poompradub, S. (2014). Styrene grafted natural rubber reinforced by in situ silica generated via sol-gel technique. Materials Science and Engineering $B$, 181, 39-45. http://dx.doi.org/10.1016/j.mseb.2013.11.018.

12. Lin, J., Wu, X., Zheng, C., Zhang, P., Huang, B., Guo, N., \& Jin, L. Y. (2014). Synthesis and properties of epoxy-polyurethane/ silica nanocomposites by a novel sol method and in-situ solution polymerization route. Applied Surface Science, 303, 67-75. http://dx.doi.org/10.1016/j.apsusc.2014.02.075.

13. NPCS Board of Consultants \& Engineers. (2010). The complete book on rubber processing and compounding. India: Asia Pacific Business Press.

14. Rao, Y. Q., Munro, J., Ge, S., \& Garcia-Meitin, E. (2014). PU elastomers comprising spherical nanosilicas: Balancing rheology and properties. Polymer, 55(23), 6076-6084. http:// dx.doi.org/10.1016/j.polymer.2014.09.065.

15. Šupová, M., Martynková, G. S., \& Barabaszová, K. (2011). Effect of Nanofillers Dispersion in Polymer Matrices: A Review. Science of Advanced Materials, 3(1), 1-25. http:// dx.doi.org/10.1166/sam.2011.1136.

16. Mokhothu, T. H., Luyt, A. S., \& Messori, M. (2014). Reinforcement of EPDM rubber with in situ generated silica particles in the presence of a coupling agent via a sol - gel route. Polymer Testing, 33, 97-106. http://dx.doi.org/10.1016/j. polymertesting.2013.11.009.

17. Poompradub, S., Thirakulrati, M., \& Prasassarakich, P. (2014). In situ generated silica in natural rubber latex via the sol-gel technique and properties of the silica rubber composites. Materials Chemistry and Physics, 144(1-2), 122-131. http:// dx.doi.org/10.1016/j.matchemphys.2013.12.030.

18. Dick, J. S., Harmon, C., \& Vare, A. (1999). Quality assurance of natural rubber using the rubber process analyzer. Polymer Testing, 18(5), 327-362. http://dx.doi.org/10.1016/S01429418(98)00026-9.

19. Fröhlich, J., Niedermeier, L. H. D., \& Luginsland, H. D. (2005). The effect of filler-filler and filler-elastomer interaction on rubber reinforcement. Composites. Part A, Applied Science and Manufacturing, 36(4), 449-460. http://dx.doi.org/10.1016/j. compositesa.2004.10.004.

20. Bezerra, F. O., Nunes, R. C. R., Gomes, A. S., Oliveira, M. G., \& Ito, E. N. (2013). Efeito Payne em nanocompósitos de nbr com montmorilonita organofílica. Polímeros: Ciência e Tecnologia, 23(2), 223-228. http://dx.doi.org/10.4322/S010414282013005000022.

21. Ramier, J., Gauthier, C., Chazeau, L., Stelandre, L., \& Guy, L. (2007). Payne effect in silica-filled styrene-butadiene rubber: Influence of surface treatment. Journal of Polymer Science. Part B, Polymer Physics, 45(3), 286-298. http://dx.doi.org/10.1002/ polb.21033.

Received: Nov. 14, 2014

Revised: Feb. 16, 2016

Accepted: Apr. 28, 2016 